\title{
Short-Term Effects of Screening for Cardiovascular Risk in the Deaf Community: A Pilot Study
}

\author{
J. V. Patel, ${ }^{1}$ P. S. Gill, ${ }^{2}$ J. Chackathayil, ${ }^{1}$ H. Ojukwu, ${ }^{3}$ P. Stemman, ${ }^{4}$ L. Sheldon, ${ }^{5}$ \\ S. Meelu, ${ }^{3}$ D. A. Lane, ${ }^{1}$ I. Tracey, ${ }^{1}$ G. Y. H. Lip, ${ }^{1}$ and E. A. Hughes ${ }^{1}$ \\ ${ }^{1}$ Sandwell Medical Research Unit, Sandwell and West Birmingham Hospitals NHS Trust, West Midlands B17 4HJ, UK \\ ${ }^{2}$ Primary Care Clinical Sciences, University of Birmingham, Birmingham B15 2TT, UK \\ ${ }^{3}$ Sandwell Primary Healthcare, B70, UK \\ ${ }^{4}$ SignHealth, Buckinghamshire, HP9, UK \\ ${ }^{5}$ Sandwell Metropolitian Borough Council, Adults and Community Services, Oldbury B69 3DE, UK
}

Correspondence should be addressed to J. V. Patel, jeeteshp@gmail.com

Received 25 October 2010; Accepted 26 January 2011

Academic Editor: Brian Olshansky

Copyright ( $) 2011$ J. V. Patel et al. This is an open access article distributed under the Creative Commons Attribution License, which permits unrestricted use, distribution, and reproduction in any medium, provided the original work is properly cited.

\begin{abstract}
There is limited information on the risk of cardiovascular disease amongst the Deaf community. Given that the access of Deaf people to mainstream health promotion is likely to be hindered by language barriers, we were interested to assess the short-term impact of cardiovascular health promotion within this group. Using a pilot study we investigated changes in cardiovascular risk factors amongst Deaf people identified to be at high cardiovascular risk, who received standard health promotion by a medical team specializing in cardiovascular health promotion. The short-term impact of cardiovascular health promotion in this group did not reduce estimates of cardiovascular risk. The reasons for this are likely to relate to the design and delivery of health promotion to Deaf people, which deserves further study.
\end{abstract}

\section{Introduction}

Cardiovascular disease (CVD) is the leading preventable cause of death in the United Kingdom (UK) [1] and a major source and symptom of health inequalities [2]. National data suggests that current healthcare services are flawed with regard to equitable healthcare for non-English speaking communities in Britain, with one specific example being the availability and utility of bilingual services $[2,3]$. There are no definitive statistics on the number of deaf people in the UK. Estimates for the number of people with severe to profound deafness range as high as 688,000, and 1 in 1,000 newborns are profoundly deaf (between 71 and 90 decibels of hearing loss), and 1 in 750 newborns are severely deaf ( $>90$ decibels of hearing loss) [4] (the term Deaf, is used here to describe those people who call themselves Deaf (with an upper case "D"), who usually use sign language as their first language and consider themselves "culturally" deaf, that is, a difference in human experience rather than a disability). Estimates for the number of deaf people who use
British Sign Language as their first of preferred language vary between 25,000 and 75,000 [5]. Deaf people, including those who are severely deaf, and profoundly deaf have an average reading age of 8 to 9 years [6]. Access to basic CVD health information is a prerequisite for Deaf people to gain the self-confidence needed to make positive lifestyle choices [7], and the delivery of such education has been highlighted as a healthcare priority for this community in the US [8]. In the UK, health promotion strategies for CVD prevention focus on the early recognition, assessment, and reduction of risk factors in asymptomatic individuals [9]. Language barriers to mainstream healthcare, in ethnic minority community groups promote a risk for poor CVD outcomes [10], but there is a lack of information on the risk of CVD amongst Deaf people in the UK. Moreover, the impact of CVD health promotion in this group remains unknown.

Based on these limitations of existing data, we sought to determine the short-term impact of CVD health promotion and assessment on 10-year coronary heart disease (CHD) risk score estimates amongst a community of Deaf people 
in the UK. We conducted a community-based assessment of CVD risk, through an outreach programme called Healthy Hearts. We hypothesised a significant reduction in CHD risk score estimates following CVD risk assessment and associated health promotion within the Deaf community. It was anticipated that such information would be important for national and international strategies that increase efforts to identify individuals at increased CVD risk at an earlier stage [11].

\section{Materials and Methods}

As part of the community CVD risk assessment programme known as "Healthy Hearts", we developed a health screening approach that was tailored for the local deaf community (Sandwell Deaf Community Association (SDCA), West Midlands, UK). Details of the organisation of Healthy Hearts events and the recruitment of subjects for this community risk assessment programme have been previously described [12]. Essential features of the Healthy Hearts community risk assessment include: (i) the involvement of the local community to develop and advertise the health screening events, (ii) the presence of an experienced physician with special interest in CVD (to deliver immediate attention to adverse findings), and (iii) the use of an interpreter and multilingual staff, who, where possible, are available to assist prospective participants to make informed choices in their involvement in the health screen, and improve communication during consultations. For this particular event, representatives of SDCA engaged with the Deaf community to promote the event. All Deaf people of SDCA were invited and recruited to participate in the health assessments. The Healthy Hearts team worked closely with SDCA to organize interpreters, appointment schedules and to gain awareness of considerations when interacting with Deaf people. The CVD risk screening events were held within existing Deaf community venues between April 2008 and March 2009. In addition to a CVD health assessment, the events included health promotion relating to dietary intake, physical activity and general wellbeing.

2.1. Cardiovascular Health Assessment. Assessments started with an explanation of the health screen and the completion of an informed choice and consent form administered by our healthcare professionals in the presence of an interpreter. A medical (cardiovascular) history was taken and a lipid profile (total, HDL cholesterol, LDL cholesterol, and triglycerides), liver function tests (alanine aminotransferase, aspartate amino transferase) blood glucose were all measured on capillary blood samples using an approved LDX cholesteck Pointof-Care device (Inverness Medical, Stockport, UK). Obesity was assessed centrally (waist and hip) using Teflon measuring tapes (guidance and definitions from the International Society for the Advancement of Kinanthropometry) and general obesity (height and weight) using Seca (Birmingham, UK) scales. The waist was the narrowest circumference above the umbilicus and below the ribs. The hip was taken as the widest horizontal circumference around the buttocks. Blood pressure was measured after the patient was seated for more than five minutes using the OMRON 705CP (Omron Healthcare Europe, Mannheim, Germany), a semi automated blood pressure monitor used with appropriate cuff sizes. The blood pressure was measured in triplicate, and the mean was calculated. Smoking habit (more than 100 cigarettes smoked in total during their lifetime) was assessed. Diabetes was defined as a self-reported history (participants knowledge of a diagnosis of diabetes by a doctor or a health professional). A history of cardiovascular disease was taken as anyone with a previous myocardial infarction, angina, atrial fibrillation, stroke, transient ischaemic attack, peripheral vascular disease, heart failure, or any coronary intervention procedure. The consent process and proforma were approved by Sandwell Local Research Ethics Committee.

2.2. Risk Calculation and Definition of High Risk. The absolute risk (\%) of developing nonfatal CHD or coronary death over the next 10 years was estimated using the algorithm derived from the Framingham Heart Study (based on the risk factors age, gender, smoking status, systolic blood pressure, total cholesterol levels, HDL cholesterol, left ventricular hypertrophy and diabetes status) [13]. All subjects were seen by a physician specialising in cardiovascular medicine, who communicated the significance of their results. CVD risk reduction advice (based on consensus guidelines from the Joint British Societies [9] was tailored to individuals' risk profile and circumstances. Subjects deemed "high risk" were further referred to the patient's own primary healthcare physician (or secondary healthcare as appropriate), when the following were observed: CHD risk score $>20 \%$, elevated blood pressure $(>140 / 90 \mathrm{mmHg})$, elevated total cholesterol $(>5 \mathrm{mmol} / \mathrm{L})$, or elevated fasting capillary blood sugar $(>6 \mathrm{mmol} / \mathrm{L})$. All subjects received general dietary and lifestyle advice from a nutritionist based in primary healthcare.

2.3. Statistical Analyses. Sample sizes for a paired $t$-test were estimated from published data on CHD risk in other communities [12]. At a 5\% type I error rate, and $80 \%$ power, we estimated that 20 subjects would be sufficient to detect moderate differences (15\%) in CHD risk scores on follow-up. We computed the change from baseline to followup in each measured variable; variables with highly skewed distributions were log-transformed before this calculation. We compared 20 high-risk subjects on change from baseline using paired $t$-test. All tests were two-tailed and performed at a significance level of .05. Statistical analyses were performed using SPSS version 14 (SPSS Inc., Chicago, IL).

\section{Results}

All clients of SDCA attended the assessments. Forty-two subjects in total were enrolled for CVD risk assessment and health promotion, and 20 high-risk subjects were followed up at 6 months. All subjects completed the CVD risk assessment. One female subject was known to have diabetes and one female was on statin therapy. The baseline 
TABLE 1: Baseline demographic characteristics for the study population. Data are percent $(n)$ or mean (sd) or * median (interquartile range).

\begin{tabular}{|c|c|c|c|c|c|c|}
\hline \multirow{2}{*}{ Cardiovascular risk factors } & \multicolumn{2}{|c|}{ Male $(n=16)$} & \multicolumn{2}{|c|}{ Female $(n=26)$} & \multicolumn{2}{|c|}{ All $(n=42)$} \\
\hline & Mean & $\mathrm{SD}$ & Mean & $\mathrm{SD}$ & Mean & SD \\
\hline Age (years) & 56.4 & 17.6 & 54.8 & 12.2 & 55.4 & 14.3 \\
\hline$\%(n)$ Hypertension & 31.2 & $(5)$ & 19.2 & $(5)$ & 23.8 & $(10)$ \\
\hline$\%(n)$ Smoking & 25.0 & (4) & 11.5 & (3) & 16.7 & $(7)$ \\
\hline Body-mass index $\left(\mathrm{kg} / \mathrm{m}^{2}\right)$ & 28.8 & 7.4 & 30.6 & 6.8 & 30.00 & 6.97 \\
\hline Waist to hip ratio & 0.971 & 0.059 & 0.911 & 0.048 & 0.934 & 0.059 \\
\hline Systolic blood pressure (mmHg) & 138 & 17 & 135 & 24 & 136.4 & 21.6 \\
\hline Diastolic blood pressure (mmHg) & 80.5 & 8.5 & 79.0 & 11.9 & 79.5 & 10.6 \\
\hline Random capillary glucose $(\mathrm{mmol} / \mathrm{L})$ & 5.79 & 1.28 & 5.23 & 0.67 & 5.44 & 0.97 \\
\hline Total cholesterol $(\mathrm{mmol} / \mathrm{L})$ & 5.00 & 1.31 & 5.14 & 1.03 & 5.09 & 1.13 \\
\hline HDL cholesterol (mmol/L) & 1.13 & 0.30 & 1.44 & 0.46 & 1.33 & 0.43 \\
\hline LDL cholesterol (mmol/L) & 3.15 & 1.25 & 2.92 & 0.94 & 3.00 & 1.05 \\
\hline Triglyceride $(\mathrm{mmol} / \mathrm{L})^{*}$ & 1.59 & $1.01-2.22$ & 1.58 & $1.07-2.05$ & 1.59 & $1.06-2.10$ \\
\hline Total cholesterol to HDL-cholesterol ratio & 4.8 & 2.0 & 4.0 & 1.0 & 4.2 & 1.5 \\
\hline Aspartate amino transferase $(\mathrm{g} / \mathrm{l})$ & 31.5 & 5.7 & 26.5 & 6.7 & 28.5 & 6.7 \\
\hline Alanine amino transferase $(\mathrm{g} / \mathrm{l})$ & 29.4 & 13.6 & 24.1 & 7.4 & 26.2 & 10.5 \\
\hline $\begin{array}{l}\text { 10-year coronary heart disease risk estimate } \\
(\%)\end{array}$ & 12.1 & 9.4 & 6.1 & 4.5 & 8.30 & 7.18 \\
\hline$\%(n)$ high coronary heart disease risk ${ }^{* *}$ & 43.8 & 7 & 50.0 & 13 & 47.6 & 20 \\
\hline
\end{tabular}

Data mean and SD, except for percentages, which are shown as percent $(n)$ and $*$ median and interquartile range; $* *$ coronary heart disease risk score $>20 \%$, elevated blood pressure ( $>140 / 90 \mathrm{mmHg})$, elevated total cholesterol ( $>5 \mathrm{mmol} / \mathrm{L})$, or elevated fasting capillary blood sugar $(>6 \mathrm{mmol} / \mathrm{L})$.

demographic characteristics for the study population are shown in Table 1.

\subsection{Self Reported Self-Care and Mobility during the CVD Risk} Assessment. During the CVD risk assessment at baseline, 16 subjects (4 males and 12 females) reported some problems in walking. Six of the subjects (14\% of the group, 1 male and 5 females) reported difficulty in washing and dressing (self-care). Sixteen subjects $(38 \%)$ reported no problems in mobility and 27 of the subjects $(64 \%)$ had no problems with self-care.

\subsection{Effects of the CVD Risk Assessment and Health Promotion} on CVD Risk Factors. A total of 20 high-risk subjects were followed up for CVD risk assessment at 6 months. The mean age was 62.3 years for men $(n=7)$ and 57.5 years for females $(n=13)$. The baseline and follow-up values of CVD risk factors are shown in Table 2. Among the 20 high-risk subjects following CVD risk assessment at 6 months, there was a significant reduction in HDL cholesterol, mean (SD) $1.43(0.51)$ versus $1.14(0.52)(P=.01)$ and a significant increase in total cholesterol to HDL cholesterol ratio, 4.2 (2.0) versus 5.8 (4.0) $(P=.007)$. The 10 -year CHD risk increased significantly, $9.2(8.4)$ versus $12.1(8.6)(P=.01)$.

\section{Discussion}

In our study of Deaf people found to be at high CVD risk, health promotion following an assessment of their risk did not achieve a reduction of risk. The study highlighted important considerations for the design and delivery of CVD health promotion within this group.

The key limitations of this study are its size, and the opportunistic nature of our community-based approach. The representativeness of this local sample of Deaf people remains unknown. Sandwell is a severely deprived area of the UK [14] where health is generally poor [15]. The impact of advice on CVD risk reduction and cardiovascular health promotion may also have been influenced by factors not measured here, such as the hearing status of parents and education. There is a lack of information on the risk of CVD amongst Deaf people in the UK. As such, data on CVD risk factors presented here cannot be compared to other studies of Deaf people. A reduction in HDL cholesterol was a key observation amongst individuals at follow-up. HDL cholesterol was determined using a direct method on capillary blood. There are increasing concerns raised with respect to serum HDL cholesterol determination using direct measurement methods [16]. However, the point of care method used here is based on a traditional precipitation method, and is established to be within acceptable ranges for accuracy and precision. Other limitations include the measurement of left ventricular hypertrophy, which was not assessed as part of the CVD risk assessment, but its presence increases the estimate for the CHD risk score.

The reading age of Deaf people in the UK [6] and the US [17] identifies a limit in the level of English vocabulary for many Deaf people [18]. The ability to communicate health promotion or education relating to CVD at this vocabulary 
TABLE 2: Baseline and 6 month follow-up of cardiovascular risk factors amongst 20 high risk Deaf people. ${ }^{\#}$ median (interquartile range).

\begin{tabular}{lccc}
\hline Risk Factors & Mean (SD) baseline value & Mean (SD) follow-up value & $P$ value \\
\hline Weight $(\mathrm{kg})$ & $89.4(23)$ & $89.0(23)$ & .181 \\
Blood pressure $(\mathrm{mmHg})$ & & & .459 \\
Systolic & $130.7(17.8)$ & $833.2(19.4)$ & .248 \\
Diastolic & $77.7(10.6)$ & $5.37(1.2)$ & .785 \\
Total cholesterol (mmol/L) & $5.33(1.2)$ & $1.14(0.52)$ & .010 \\
HDL-cholesterol (mmol/L) & $1.43(0.51)$ & $3.18(0.88)$ & .304 \\
LDL-cholesterol $(\mathrm{mmol} / \mathrm{L})$ & $3.04(0.75)$ & $0.49(0.49)$ & .167 \\
Triglycerides ${ }^{*}(\mathrm{mmol} / \mathrm{L})$ & $0.39(0.49)$ & $5.69(1.20)$ & .539 \\
Fasting glucose $(\mathrm{mmol} / \mathrm{L})$ & $5.50(0.87)$ & $5.8(4.0)$ & .007 \\
Total cholesterol to HDL-cholesterol ratio & $4.2(2.0)$ & $11.8(6.9-17.1)$ & .013 \\
10-year CHD risk estimates $(\%)$ & $5.4(3.9-14.6)$ & &
\end{tabular}

level is very difficult. Irrespective of the vocabulary of Deaf people, sign language also appears to be underdeveloped. An example that arose during health consultations was that there was no sign for cholesterol. Similarly, many Deaf people have difficulty in reading given the crucial role of language sound (phonological awareness) when learning to read. This difficulty is further heightened through the lack of access to a fully accessible language learning environment. Hence, due to these language barriers, many Deaf people are denied the most basic of health promotion known to save lives. While there is likely to be variation in the intensity of health promotion that high risk individuals received from their general practitioners following our referral, the intention of this study was to focus on the communication of basic CVD health promotion in this community. It appeared that there had been little exposure to cardiovascular health promotion in this group from conventional sources. Unfamiliarity with heart disease risk factors because of a previous lack of exposure may well have contributed to greater CVD risk within this group and lessened the impact of a single point intervention.

We are tempted to speculate that these language barriers contribute to CVD risk within this group. The risk of CVD is also likely to be higher in Deaf people of the UK. In comparison with data on CVD risk amongst nondeaf communities in Sandwell [12], cholesterol levels and BMI appeared higher in Deaf people. In the general hearing population, in areas of raised socioeconomic deprivation, CVD risk assessment is likely to underestimate risk [19]. A sound population approach is needed to identify whether CVD risk is raised in Deaf people. Nonetheless, given the impact of language barriers on CVD risk reported here, CVD health promotion should be seen as a priority in this group in the UK (as in the US) [8].

In conclusion, the short-term impact of CVD risk assessment and associated health promotion in this group did not reduce CHD risk estimates. The design and delivery of CVD health promotion specific to Deaf people deserves further study given that this group appears to be at an increased risk.

\section{Funding}

Sandwell Primary Healthcare Trust and the Department of Health (Testbed evaluation).

\section{Disclosures}

We confirm that none of the authors have a conflict of interest to declare, fully support the submission, and that this submission includes original work that has not been published previously, and it is not under consideration for publication elsewhere.

\section{Acknowledgments}

The authors are grateful for the support from Sandwell Deaf Community Association and from Ruth Lambley-Burke and Kamini Patel for support with the cardiovascular health screens.

\section{References}

[1] British Heart Foundation Statistics, 2009, http://www .heartstats.org.

[2] P. S. Gill, J. Kai, R. S. Bhopal, and S. Wild, "Health care needs assessment: black and minority ethnic groups," in Health Care Needs Assessment: The Epidemiologically Based Needs Assessment Reviews, J. Raftery, Ed., 3rd Series, Radcliffe Medical Press, Abingdon, UK, 2007.

[3] P. S. Gill, A. Shankar, T. Quirke, and N. Freemantle, "Access to interpreting services in England: secondary analysis of national data," BMC Public Health, vol. 9, article 12, 2009.

[4] Royal National Institute for the Deaf, 2009, http://www.rnid .org.uk/information_resources/aboutdeafness/statistics/ statistics.htm.

[5] Sign of the Times Department of Health, 2003, www.nimhe .org.uk/downloads/signoftimes.pdf.

[6] Sterne A Deafness and reading, 2009, http://www.literacytrust .org.uk/pubs/stern.htm.

[7] A. Middleton, A. Niruban, G. Girling, and P. K. Myint, "Communicating in a healthcare setting with people who have 
hearing loss," British Medical Journal, vol. 341, article c4672, 2010.

[8] H. Margellos-Anast, M. Estarziau, and G. Kaufman, "Cardiovascular disease knowledge among culturally Deaf patients in Chicago," Preventive Medicine, vol. 42, no. 3, pp. 235-239, 2006.

[9] British Cardiac Society, British Hypertension Society, Diabetes UK, HEART UK, Primary Care Cardiovascular Society, Stroke Association, "JBS 2: Joint British Societies' guidelines on prevention of cardiovascular disease in clinical practice," Heart, vol. 91, supplement 5, pp. v1-v5, 2005.

[10] G. Y. H. Lip, A. H. Barnett, A. Bradbury et al., "Ethnicity and cardiovascular disease prevention in the United Kingdom: a practical approach to management," Journal of Human Hypertension, vol. 21, no. 3, pp. 183-211, 2007.

[11] Department of Health, 2009, http://www.dh.gov.uk/en/ Healthcare/NationalServiceFrameworks/Vascular/ NHShealthcheck/DH_088799.

[12] J. V. Patel, A. Gunarathne, D. Lane et al., "Widening access to cardiovascular healthcare: community screening among ethnic minorities in inner-city Britain-The Healthy Hearts Project," BMC Health Services Research, vol. 7, article 192, 2007.

[13] K. M. Anderson, P. W. F. Wilson, P. M. Odell, and W. B. Kannel, "An updated coronary risk profile. A statement for health professionals," Circulation, vol. 83, no. 1, pp. 356-362, 1991.

[14] National Statistics Online. UK census, 2004, http://www .statistics.gov.uk.

[15] Department of Health, community health profile, 2007, http://www.communityhealthprofiles.info/profiles/hp2007/ lo_res/00CS-HP2007.pdf.

[16] W. G. Miller, G. L. Myers, I. Sakurabayashi et al., "Seven direct methods for measuring HDL and LDL cholesterol compared with ultracentrifugation reference measurement procedures," Clinical Chemistry, vol. 56, no. 6, pp. 977-986, 2010.

[17] E. G. Jones, R. Renger, and R. Firestone, "Deaf community analysis for health education priorities," Public Health Nursing, vol. 22, no. 1, pp. 27-35, 2005.

[18] R. Q. Pollard, "Psychopathology," in Psychological Perspectives on Deafness, M. Marschark and M. D. Clark, Eds., vol. 2, pp. 171-197, Lawrence Erlbaum, Mahwah, NJ, USA, 1998.

[19] P. M. Brindle, A. McConnachie, M. N. Upton, C. L. Hart, G. D. Smith, and G. C. M. Watt, "The accuracy of the Framingham risk-score in different socioeconomic groups: a prospective study," British Journal of General Practice, vol. 55, no. 520, pp. 838-845, 2005. 


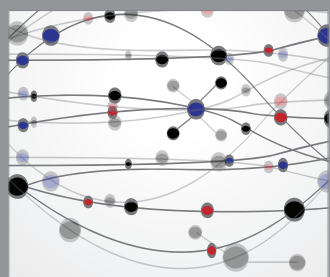

The Scientific World Journal
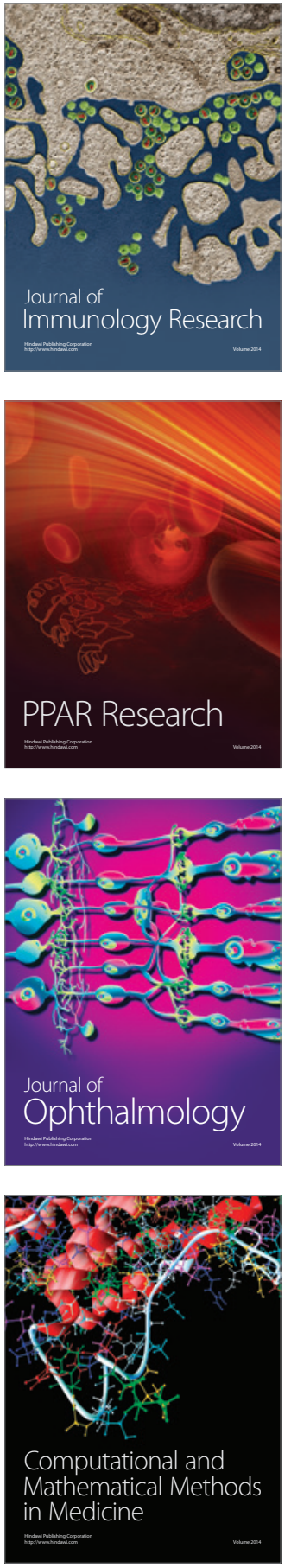

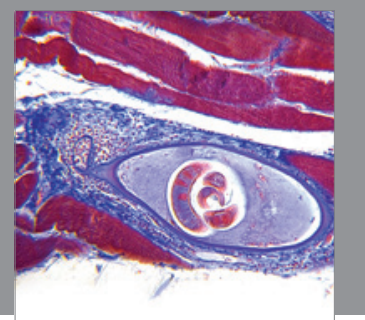

Gastroenterology

Research and Practice
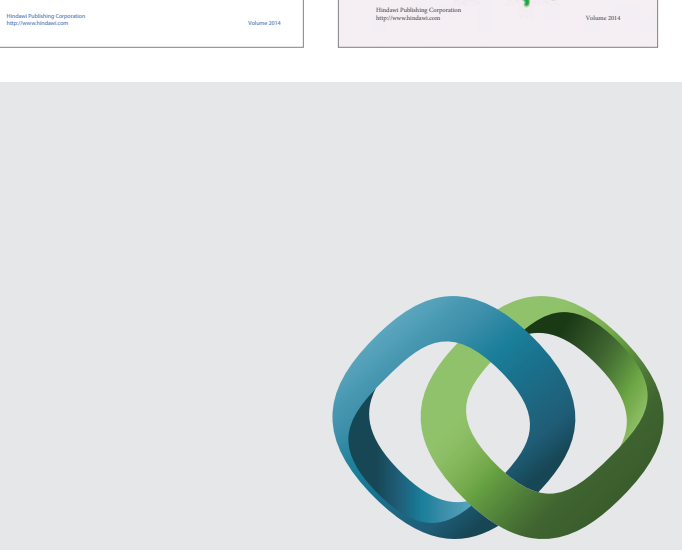

\section{Hindawi}

Submit your manuscripts at

http://www.hindawi.com
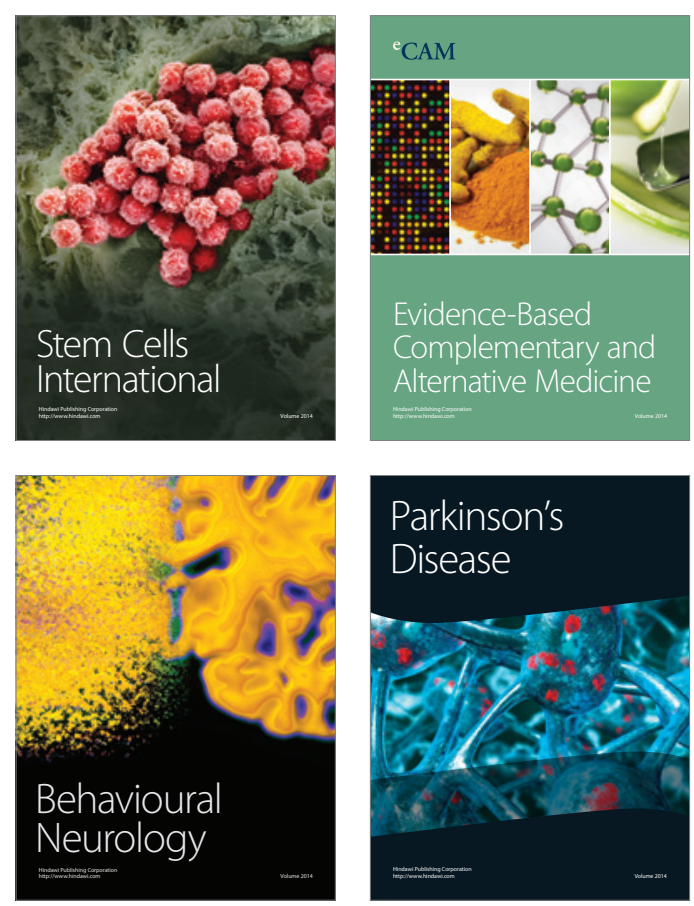

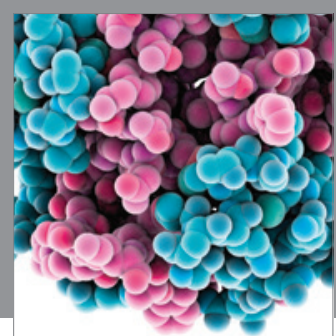

Journal of
Diabetes Research

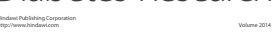

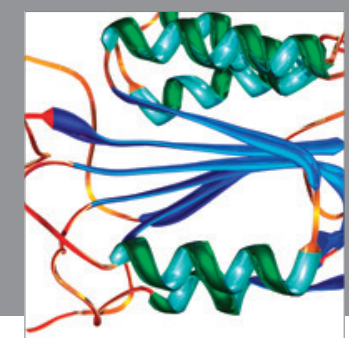

Disease Markers
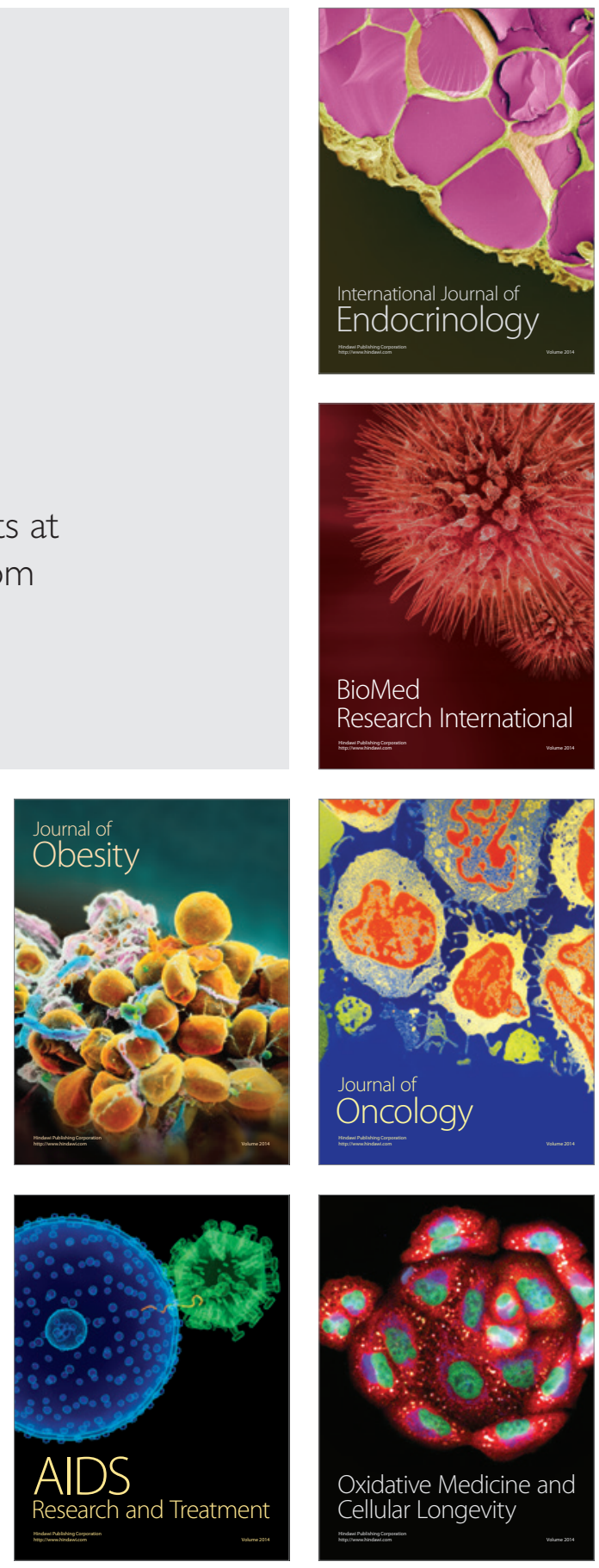